\title{
A Comparative Study of Emotion Word Production Between Sundanese Females and Males
}

Nabilah Puteri Sulaemana, Azzahrah Venusyah Kantri ${ }^{\mathrm{b}}$, Hendrick Wijaya Hartono $^{\mathrm{c}}$, and Tiara R. Widiastuti ${ }^{\mathrm{d}}$

${ }^{a}$ Faculty of Psychology, Universitas Padjajaran, Sumedang, West Java, Indonesia; ${ }^{b}$ Faculty of Psychology, Universitas Padjajaran, Sumedang, West Java, Indonesia; ${ }^{c}$ Faculty of Psychology, Universitas Padjajaran, Sumedang, West Java, Indonesia; $d_{\text {Faculty of }}$ Psychology, Universitas Padjajaran, Sumedang, West Java, Indonesia

*Corresponding author:

Nabilah Puteri Sulaeman

Faculty of Psychology, Universitas Padjadjaran

Jl. Raya Bandung-Sumedang Km. 21,

Jatinangor

Sumedang, West Java 45363 - Indonesia

Tel.: +62 227794126

Email address: nabilah15007@mail.unpad.ac.id 


\title{
A Comparative Study of Emotion Word Production Between Sundanese Females and Males
}

\begin{abstract}
There is a difference between how males and females use language. However, there are only a limited number of research comparisons of emotion word production between females and males. This study aims to identify the comparison of emotion word production among females and males using Plutchik's emotion theory. Data were collected using survey methods, during which researchers asked the participants to list the words that could be used to describe a feeling. Results show that there were three basic emotions and three mixed emotions in most female participants' answers. Similarly, in most male participants' answers, there were also three basic emotions and three mixed emotions, but with different basic emotions presented.
\end{abstract}

Keywords: gender, Sundanese, emotions, emotion words

\section{Introduction}

There is a difference between how males and females use language. Studies regarding this issue indicate that females tend to produce more words related to psychological cognitive processes to convey their emotions, while males tend to produce more cultural and context related words (Mei-Rong, Hsieh, 2007; Newman, Groom, Handelman, \& Pennebaker, 2008). In other studies, females talked more about feelings and made more emotional references during interpersonal speech tasks than did males (Girdler, Turner, Sherwood, \& Light, 1990). In Hutasuhut (2016), Tannen (1990) stated that males and females have different forms of communication. Males tend to use language to gain status, while females use the language to negotiate closeness and intimacy. Females use rapport talk to build and maintain relationships, while men use report talk to communicate factual information (Ishikawa, 2015).

The Sundanese ethnic group is one of the few ethnic groups in Indonesia without numerous ethnic sub-groups and whose people still relate strongly enough to their culture to have a cultural self (Ninin, 2015). They number approximately 40 million and form Indonesia's second most populous ethnic group after the Javanese. The Sundanese have traditionally been concentrated in the provinces of West Java, Banten, Jakarta, and the western part of Central Java. Sundanese migrants can also be found in Lampung and South Sumatra, and to a lesser extent in Central Java and East Java. Sundanese make up around 15.5\% of Indonesia's population (BPS, 2011). Sundanese people have some particular characteristics, such as being outspoken, subjective or subject-related, substantial, humorous, emotional, indirect, indistinct, polite, sensitive, and loyal. These characteristics have been obtained from the language expression they use to express their feelings (Sudaryat, 2015). It clearly explained how these characteristics were obtained from their use of syntax and other language components.

Because what is seen in a culture will be reflected in the language (Sudaryat, 2015), these findings prove how Sundanese culture affects their use of language, specifically regarding emotion words, to express their emotions. Culturally, Sundanese people have adopted a bilateral kinship system in which males and females are of equal importance (Hustahut, 2016). The 
limited number of research comparisons of emotion word production between females and males has inspired further studies regarding this issue. The main aim is to identify the differences of emotion word production among females and males, especially among the Sundanese, using Plutchik's emotion theory. There are eight basic emotions (Plutchik, 2000). The basic emotions are joy, acceptance, fear, surprise, sadness, disgust, anger, and anticipation. The combination of two emotions produces a mixed emotion. For example, the combination of joy and acceptance produces the mixed emotion of love (Plutchik, 2000).

\section{Methods}

The research design used in this study was comparative and under the field of ethnographic studies that specifically explores the emotion words produced by the Sundanese. The sampling method of this study was purposive sampling (Christensen, Johnson, \& Turner, 2011). 103 Sundanese, composed of 30 males and 80 females, participated in this study. All participants were 13-56 years old $(M=25$ years old; $S D=11.8)$. The ages of the males ranged from 16-56 years old $(\mathrm{M}=29.2$ years old; $\mathrm{SD}=13.7)$. The age of the females ranged from 13-52 years old $(M=23.1$ years old; $S D=10.5)$. Data were collected using survey methods. Researchers asked the participants to list the words that could be used to describe a feeling. Each item was a written question, such as, "Write words that can be used to describe the feelings in the empty section below." Then, each researcher coded the data separately. Each researcher coded the list of words into several emotions based on Plutchik's theory of emotion. After that, codes were checked for agreement. Finally, the frequencies of the emotions that appeared in our data were counted. This process was done using a QDA Miner Lite vr.2.0.5.

\section{Results}

Results show that there were three basic emotions and three mixed emotions in most female participants' answers, including joy, sadness, anger, caution, disappointment, and anxiety. Similarly, in most male participant's answers, there were three basic emotions and three mixed emotions, including joy, sadness, anger, disappointment, love, and caution. Among the female participants, about 29 words were used to represent joy ("senang" and "bahagia" were the most frequently used); 69 words to represent sadness ("sedih" and "galau" were the most frequently used); 32 words to represent anger ("marah" and "kesal" were the most frequently used); 24 words to represent caution ("bingung" and "bimbang" were the most frequently used); 9 words to represent disappointment ("kecewa" and "kacau" were the most frequently used); and 15 words to represent anxiety ("cemas," "deg-degan," and "khawatir" were the most frequently used). Meanwhile, among the male participants about 19 words were used to represent joy ("senang" and "bahagia" were the most frequently used); 31 words to represent sadness ("sedih" and "sakit" were the most frequently used); 17 words to represent anger ("marah" and "kesal" were the most frequently used); 6 words to represent disappointment ("kecewa" and "Astagfirullah" were the most frequently used); 7 words to represent love ("cinta" and "sayang" were the most frequently used); and 15 words to represent caution ("bingung" and "galau" were the most frequently used) (see Table I and Table II). 
Table I. Most Displayed Emotions

\begin{tabular}{|c|c|c|c|c|}
\hline Gender & Category & Emotion & Description & Total $(\%)$ \\
\hline \multirow[t]{6}{*}{ Female } & \multirow[t]{3}{*}{ Basic Emotion } & Joy & & $71(98.60 \%)$ \\
\hline & & Sadness & & $69(95.80 \%)$ \\
\hline & & Anger & & $64(88.90 \%)$ \\
\hline & \multirow[t]{3}{*}{$\begin{array}{l}\text { Mixed } \\
\text { Emotion }\end{array}$} & Caution & $\begin{array}{l}\text { Anticipation + } \\
\text { Fear }\end{array}$ & $55(76.40 \%)$ \\
\hline & & Disappointment & Surprise + Sadness & $40(55.60 \%)$ \\
\hline & & Anxiety & $\begin{array}{l}\text { Anticipation + } \\
\text { Fear }\end{array}$ & $37(51.40 \%)$ \\
\hline \multirow[t]{6}{*}{ Male } & \multirow[t]{3}{*}{ Basic Emotion } & Joy & & $29(96.70 \%)$ \\
\hline & & Sadness & & $28(93.30 \%)$ \\
\hline & & Anger & & $21(70.00 \%)$ \\
\hline & \multirow{3}{*}{$\begin{array}{c}\text { Mixed } \\
\text { Emotion }\end{array}$} & Disappointment & Surprise + Sadness & $16(53.30 \%)$ \\
\hline & & Love & Joy + Acceptance & $15(50.00 \%)$ \\
\hline & & Caution & $\begin{array}{l}\text { Anticipation + } \\
\text { Fear }\end{array}$ & $14(46.70 \%)$ \\
\hline
\end{tabular}

Table II. Most Frequent Words used to Represent Emotion

\begin{tabular}{|c|c|c|c|c|}
\hline Gender & Category & Emotion & $\begin{array}{l}\text { Number of } \\
\text { words }\end{array}$ & $\begin{array}{l}\text { Frequently used } \\
\text { words }\end{array}$ \\
\hline \multirow[t]{6}{*}{ Female } & \multirow[t]{3}{*}{ Basic Emotion } & Joy & 29 & $\begin{array}{l}\text { "senang" and } \\
\text { "bahagia" }\end{array}$ \\
\hline & & Sadness & 69 & "sedih" and "galau" \\
\hline & & Anger & 32 & "marah" and "kesal" \\
\hline & \multirow[t]{3}{*}{ Mixed Emotion } & Caution & 24 & $\begin{array}{l}\text { "bingung" and } \\
\text { "bimbang" }\end{array}$ \\
\hline & & Disappointment & 9 & "kecewa" and "kacau" \\
\hline & & Anxiety & 15 & $\begin{array}{l}\text { "cemas," "deg-degan," } \\
\text { and "khawatir" }\end{array}$ \\
\hline \multirow[t]{3}{*}{ Male } & \multirow[t]{3}{*}{ Basic Emotion } & Joy & 19 & $\begin{array}{l}\text { "senang" and } \\
\text { "bahagia" }\end{array}$ \\
\hline & & Sadness & 31 & "sedih" and "sakit" \\
\hline & & Anger & 17 & "marah" and "kesal" \\
\hline
\end{tabular}




\begin{tabular}{|l|l|l|l|} 
Mixed Emotion & Disappointment & 6 & $\begin{array}{l}\text { "kecewa" and } \\
\text { "Astagfirullah" }\end{array}$ \\
\cline { 3 - 5 } & Love & 7 & "cinta" and "sayang" \\
\cline { 2 - 4 } & Caution & 15 & "bingung" and "galau" \\
\hline
\end{tabular}

\section{Conclusion}

This study provides several conclusions. The first is that almost all females and males produce emotion words that represent joy, sadness, and anger as their basic emotions. In contrast, the production of mixed emotion words is different between females and males. Within males, culturally related words, such as "astagfirullah" or "galau," were produced more compared to females, who used more perceptive-related words, such as "kecewa" and "bimbang." Females and males mostly used the same words to express joy, sadness, and anger. However, the total number of words produced that represent the emotions of joy, sadness, anger, disappointment, and caution was higher in females than in males.

\section{Discussion}

These findings need to be considered further as there are imbalances between the male and female participants in the research. There were more female participants, and there were only 30 male participants; it's still a concern whether these findings can be validly said to represent the whole Sundanese ethnic group.

These findings are consistent with previous studies that found females produce more words that represent emotions than males (Vainik, 2006). There is a lack of empirical evidence in studies regarding emotion word production between females and males. Although our focus was more on the production of emotion words, it offers opportunities for future research regarding when, why, and how females and males show differences in the production of emotion words and the display rules regarding the use of certain words in Sundanese and others.

Almost all females and males produce emotion words that represent joy, sadness, and anger as their basic emotions. It is said that Sundanese people are found to be friendly and humorous, and this was supported when the research showed that joy-related words, such as "senang" and "bahagia," were produced more than any other words. The production of mixed emotion words is different between females and males. Regarding the males, words related to culture, such as "astagfirullah" or "galau," were produced more than in females, who use more perceptionrelated words, such as "kecewa" and "bimbang." Females and males mostly use the same words to express joy, sadness, and anger. In general, females produce more words that represent the emotions of joy, sadness, anger, disappointment, and caution compared to males. This study provides evidence that there is a difference regarding the production of emotion words between Sundanese females and males using Plutchik's emotion theory. 


\section{References}

Badan Pusat Statistik. (2011). Kewarganegaraan, Suku Bangsa, Agama dan Bahasa Sehari-Hari Penduduk Indonesia Hasil Sensus Penduduk Indonesia 2010. Jakarta: Badan Pusat Statistik

Christensen, L. B., Johnson, B., \& Turner, L. A. (2011). Research methods, design, and analysis (11th ed). Boston, MA: Pearson Education, Inc.

Girdler, S. S., Turner, J. R., Sherwood, A., \& Light, K. C. (1990). Gender differences in blood pressure control during a variety of behavioral stressors. Psychosomatic Medicine, 52(5), 571-591.

Hutasuhut, N. I. (2016). Gender language characteristics of Twitter participants of different cultures (Doctoral dissertation). Universitas Negeri Medan, Medan, Indonesia.

Ishikawa, Y. (2015). Gender differences in vocabulary use in essay writing by university students. ProcediaSocial and Behavioral Sciences, 192, 593-600.

Mei-Rong, W., Hsieh, S. C.Y. (2007). Gender differences in the language for emotions. Asian Journal of Management and Humanity Science, 2(1-4), 89-97.

Newman, M. L., Groom, C. J., Handelman, L. D., \& Pennebaker, J. W. (2008). Gender differences in language use: An analysis of 14,000 text samples. Discourse Processes, 45(3), 211-236.

Ninin, R. H. (2015). The self of Sundanese ethnic: Interdependent construal and religious self. Asian Social Science, 11(16), 1-8.

Plutchik, R. (2000). Emotions in the practice of psychotherapy: Clinical implications of affect theories. Washington, DC: American Psychological Association Press.

Sudaryat, Y. (2016). The Mindset of Sundanese People in Their Language Expressions. Indonesian Journal of Applied Linguistics, 5(1), 126-133.

Tannen, D. (1990). You just don't understand: Women and men in conversation (p. 42). New York: Morrow.

Vainik, E. (2006). Intracultural variation of semantic and episodic emotion knowledge in Estonian. TRAMES: A Journal of the Humanities \& Social Sciences, 10(2), 169-189. 